\title{
Decreased Early Atherosclerotic Lesions in Hypertriglyceridemic Mice Expressing Cholesteryl Ester Transfer Protein Transgene
}

Tony Hayek, Lori Masucci-Magoulas, ${ }^{\star}$ Xian Jiang, ${ }^{*}$ Annemarie Walsh, Edward Rubin, ${ }^{\ddagger}$ Jan L. Breslow, and Alan R. Tall* Laboratory of Biochemical Genetics and Metabolism, The Rockefeller University, New York 10021-6399 and *Department of Medicine, Columbia University College of Physicians and Surgeons, New York 10032; and ${ }^{\ddagger}$ Life Sciences Division, Lawrence Berkeley Laboratory, University of California at Berkeley, Berkeley, California 94720

\begin{abstract}
The human cholesteryl ester transfer protein (CETP) facilitates the transfer of cholesteryl ester from HDL to triglyceride-rich lipoproteins. The activity of CETP results in a reduction in HDL cholesterol levels, but CETP may also promote reverse cholesterol transport. Thus, the net impact of CETP expression on atherogenesis is uncertain. The influence of hypertriglyceridemia and CETP on the development of atherosclerotic lesions in the proximal aorta was assessed by feeding transgenic mice a high cholesterol diet for 16 wk. 13 out of 14 (93\%) hypertriglyceridemic human apo CIII (HuCIII) transgenic (Tg) mice developed atherosclerotic lesions, compared to 18 out of $29(62 \%)$ controls. In HuCIII/CETPTg, human apo AI/CIIITg and HuAI/CIII/ CETPTg mice, 7 of $13(54 \%), 5$ of $10(50 \%)$, and 5 of 13 $(38 \%)$, respectively, developed lesions in the proximal aorta $(P<.05$ compared to HuCIIITg). The average number of aortic lesions per mouse in HuCIIITg and controls was $3.4 \pm 0.8$ and $2.7 \pm 0.6$, respectively; in HuCIII/CETPTg, HuAI/CIIITg, and HuAI/CII/CETPTg mice, the number of lesions was significantly lower than in HuCIIITg and control mice: $0.9 \pm 0.4,1.5 \pm 0.5$, and $0.9 \pm 0.4$, respectively. There were parallel reductions in mean lesion area. In a separate study, we found an increased susceptibility to dietary atherosclerosis in nonhypertriglyceridemic CETP transgenic mice compared to controls. We conclude that CETP expression inhibits the development of early atherosclerotic lesions but only in hypertriglyceridemic mice. ( $J$. Clin. Invest. 1995. 96:2071-2074.) Key words: high density lipoproteins • cholesteryl ester transfer protein • atherosclerosis $\cdot$ transgenic mouse $\cdot$ hypertriglyceridemia
\end{abstract}

Address correspondence to Alan R. Tall, Division of Molecular Medicine, Department of Medicine, Columbia University College of Physicians and Surgeons, $630 \mathrm{~W}$. 168th Street, New York, NY 10032. Phone: 212-305-4899; FAX: 212-305-5052.

Received for publication 14 April 1995 and accepted in revised form 19 July 1995.

1. Abbreviations used in this paper: $\mathrm{CE}$, cholesteryl ester; CETP, CE transfer protein; HDL-C, HDL cholesterol; HuC-III, human apo C-III; $\mathrm{Tg}$, transgenic.

J. Clin. Invest.

(c) The American Society for Clinical Investigation, Inc.

0021-9738/95/10/2071/04 \$2.00

Volume 96, October 1995, 2071-2074

\section{Introduction}

In human plasma, cholesteryl ester (CE $)^{1}$ and triglycerides are redistributed between lipoproteins by cholesteryl ester transfer protein (CETP) (1-3). In humans CETP has an important role in the catabolism of HDL, as illustrated by genetic CETP deficiency where HDL cholesterol, and apo A-I levels are elevated (4). The risk of coronary heart disease in humans is strongly inversely correlated with the plasma concentration of HDL cholesterol (HDL-C) (5-7). However, the role of CETP in the development of atherosclerosis is uncertain. Kinetic data (8) and in vitro studies (9) suggest that CETP could be antiatherogenic through transfer of HDL-CE to triglyceride-rich lipoproteins, which are subsequently cleared by the liver. On the other hand, CETP might be proatherogenic as a result of enrichment of triglyceride-rich lipoproteins with cholesteryl ester at the expense of HDL cholesterol levels.

We have been using transgenic technology to study HDL metabolism and the role of CETP in the regulation of HDL-C levels (10-13). Mice have low levels of CETP activity and the introduction of a human CETP transgene results in reduced HDL cholesterol levels (13). CETP expression has a more pronounced effect on HDL cholesterol levels in transgenic animals expressing human apo A-I (14). The introduction of the human A-I, apo C-III, and CETP genes into transgenic mice produced a high triglyceride, low HDL-C lipoprotein phenotype (15). Human apo C-III gene overexpression causes hypertriglyceridemia with a significant decrease in HDL-C and apo AI $(15,16)$. In the hypertriglyceridemic mice, human CETP gene expression caused further reduction in HDL-C and profound synergistic reduction in apo A-I levels and HDL size (15).

To study the role of hypertriglyceridemia and CETP in the development of atherosclerosis, we crossbred mice with human apo A-I, apo C-III and CETP transgenes. We examined the effects of hypertriglyceridemia with or without CETP on the background of mouse or human apo A-I on the propensity to develop atherosclerosis. We found that the presence of CETP inhibited the development of early atherosclerotic lesions in hypertriglyceridemic mice.

\section{Methods}

Transgenic mice. Transgenic mice were created as previously described $(10,13,16,17)$. The fertilized eggs injected with foreign DNA were derived from $F_{1}(C 57 B L 6 / J \times C B A / J)$ mice. Transgenic mice were confirmed by tail tip DNA analysis and mated to $F_{1}$ mice of the same genetic background. One line of human apo C-III transgenic (HuCIIITg) mice was used, 3707 . This line expresses the apo CIII transgene primarily in the liver $(>90 \%)$ with some intestinal expression; mean triglycer- 
Table I. Lipid Levels in Controls, HuC111Tg, HuC111CETPTg, HuAlC111Tg, and HuAlC111CETPTg Mice

\begin{tabular}{lccll}
\hline \multicolumn{1}{c}{ Mice } & TG & \multicolumn{1}{c}{ TC } & HDL-C & Non-HDL \\
\hline & & $m g / d l$ \\
Controls $(n=28)$ & $80 \pm 9$ & $254 \pm 12$ & $59 \pm 3$ & $195 \pm 13$ \\
HuC111Tg $(n=15)$ & $684 \pm 51$ & $395 \pm 26$ & $46 \pm 2$ & $350 \pm 27$ \\
HuC111CETPTg $(n=15)$ & $600 \pm 68$ & $333 \pm 30$ & $36 \pm 2^{*}$ & $297 \pm 30$ \\
HuA1C111Tg $(n=11)$ & $750 \pm 146$ & $324 \pm 34$ & $61 \pm 6$ & $260 \pm 31$ \\
HuA1C111CETPTg $(n=15)$ & $687 \pm 91$ & $300 \pm 19$ & $25 \pm 2^{\ddagger}$ & $274 \pm 19$
\end{tabular}

Animals ingested a high cholesterol diet + zinc sulfate $(25 \mathrm{mM})$. TC, total cholesterol; TG, triglyceride. ${ }^{*} P<0.05 ;{ }^{\ddagger} P<0.01$, as determined by ANOVA.

ide levels are $\sim 600 \mathrm{mg} / \mathrm{dl}(17)$. One line of human CETP transgenic (HuCETPTg) mice was used (13). This line was made with a DNA construction which contains a CETP minigene driven by the mouse metallothionein-1 promoter. Also, two lines of transgenic mice (4867, 4868 ) were used which contained both the human apo A-I and apo CIII genes (18). In these lines, the apo A-I transgene was expressed equally in the liver and intestines, and the apo C-III transgene was expressed primarily in the liver $(>90 \%)$. The human apo A-I and apo $\mathrm{C}$-III levels were similar in the two lines (18). The HuCIIICETPTg mice were generated by crossing HuCIIITg mouse line 3707 with HuCETPTg mice. The HuAI/CIII/CETPTg mice were generated by crossing the HuAI/CIIITg mouse lines $(4867,4868)$ with HuCETPTg mice.

Blood sampling protocol. Animals were housed with alternating 12 $\mathrm{h}$ periods of light $(7: 00 \mathrm{am}$ to 7:00 pm) and dark (7:00 pm to 7:00 am) with free access to food and water. Mice at 12-16 wk of age were given a high cholesterol diet which contained $15 \%(\mathrm{wt} / \mathrm{wt}$ ) fat (primary fat source is cocoa butter), $1.25 \%(\mathrm{wt} / \mathrm{wt})$ cholesterol, $0.5 \%(\mathrm{wt} / \mathrm{wt})$ sodium cholate and distilled water supplemented with $25 \mathrm{mM} \mathrm{ZnSO}$ to raise the level of plasma CETP. In previous studies, it was shown that the addition of zinc to the diet has no significant effect on the lipoprotein profile in the HuCIIITg mice, whereas it maximizes the effect of metallothionein promoter driven CETP transgene in the HuCIII/CETPTg mice. At the end of a period of $4 \mathrm{mo}(16 \mathrm{wk})$ treatment with high cholesterol diet, blood was collected after an overnight fasting from the retroorbital plexus under methoxyflurane anesthesia.

Histological analysis. Mice were then killed, and hearts and aortas were fixed in $4 \%$ phosphate-buffered formaldehyde for five or more days. For the quantitative assay, hearts were embedded in $25 \%$ gelatin The quantitation of atherosclerosis was performed in a blinded fashion Processing and staining of tissue were carried out according to Paigen et al. (19) and quantitation of the lesion area was performed by the modified method of Rubin et al. (20). For qualitative analysis, hearts and aortas were fixed and embedded in paraffin. Sections were cut at $6-\mu \mathrm{M}$ thickness, mounted and stained appropriately. An average of 10 sections per mouse was examined.

Plasma lipid and lipoprotein analysis. Triglyceride and total cholesterol were determined enzymatically, using Boehringer Mannheim reagents (Boehringer Mannheim Biochemicals, Indianapolis, IN). HDL and other lipoprotein fractions were separated by ultracentrifugation in an airfuge (Beckman Instruments, Inc., Fullerton, CA) as previously described (10).

Plasma and CETP concentration. Plasma CETP concentration was measured by solid phase radioimmunoassay as previously described (21).

Statistical analysis. Results are expressed as mean \pm SE of the mean. One-way ANOVA or Fisher's exact test was used to compare differences between groups.

\section{Results}

Several types of transgenic mice were used to study the influence of hypertriglyceridemia in the presence or absence of
Table II. Number of Mice with Lesions Detected in the Aorta

\begin{tabular}{lccc}
\hline Mice & $\begin{array}{c}\text { Yes } \\
\text { lesions }\end{array}$ & $\begin{array}{c}\text { No } \\
\text { lesions }\end{array}$ & $\begin{array}{c}\text { Percent of mice with } \\
\text { detected lesions }\end{array}$ \\
\hline $\begin{array}{c}\text { Controls } \\
n=29\end{array}$ & 18 & 11 & 62 \\
$\begin{array}{c}\text { HuCIIITg } \\
n=14\end{array}$ & 13 & 1 & 93 \\
$\begin{array}{c}\text { HuCIIICETPTg } \\
n=13\end{array}$ & 7 & 6 & $54^{*}$ \\
$\begin{array}{c}\text { HuAICIIITg } \\
n=10\end{array}$ & 5 & 5 & $50^{*}$ \\
HuAICIIICETPTg \\
$n=13$
\end{tabular}

The values in this table are the number of mice with lesions detected in the aorta. Statistical analysis (Fisher's exact test) indicates that the number of mice with lesions in HuCIIICETPTg and HuAICIIITg is significantly lower than in HuCIIITg mice. $* P<0.05$ in HuAICIIICETPTg mice, the number of mice with lesions is even lower than in HuCIIITg mice: ${ }^{\ddagger} P<0.005$.

CETP on a background of mouse or human apo A-I, on lipoprotein levels, and on the development of atherosclerosis. Plasma lipid and HDL cholesterol concentrations are shown in Table I. HuCIIITg and HuCIII/CETPTg mice had triglycerides in the $600-700 \mathrm{mg} / \mathrm{dl}$ range, compared to $80 \mathrm{mg} / \mathrm{dl}$ in controls. The increase of total cholesterol in these animals is primarily the result of an increase in the non-HDL cholesterol fraction (Table I). Compared to HuCIIITg mice, HuCIII/CETPTg mice had $22 \%$ lower HDL-C $(46 \pm 2$ vs $36 \pm 2 \mathrm{mg} / \mathrm{dl}, P<0.05)$, and $\mathrm{HuAI} / \mathrm{CIII} / \mathrm{CETPTg}$ mice had 59\% lower HDL cholesterol than AI/CIIITg mice $(P<0.01)$. Plasma lipoprotein profiles of controls, HuCIIITg, HuCIII/CETPTg, HuAI/CIIITg, and HuAICIII/CETPTg mice were also determined on pooled plasma samples by column chromatography (FPLC). The results were similar to those previously described (15). HuCIII/CETPTg and HuAI/CIII/CETPTg mice had a similar CETP concentration to that previously described (15).

Mice were killed at 28-32 wk of age after being challenged for $16 \mathrm{wk}$ with the atherogenic diet, and the proximal aortas were evaluated for the presence and extent of atherosclerotic lesions $(19,20,22) .13$ of $14(93 \%)$ HuCIIITg mice developed atherosclerotic lesions, compared to 18 of $29(62 \%)$ controls (Table II). The introduction of human apo A-I and/or human CETP transgenes into the HuCIIITg hypertriglyceridemic mice protected the animals against the development of atherosclerosis. In HuCIII/CETPTg, HuAI/CIIITg, and HuAI/CIII/ CETPTg mice, only 7 out of $13(54 \%), 5$ out of $10(50 \%)$, and 5 out of $13(38 \%)$, respectively, developed lesions in the proximal aorta (Table II, $P<.05, P<.05$, and $P<.005$, respectively, compared to HuCIIITg mice).

The average number of aortic lesions in the HuCIIITg and control mice was not significantly different: $3.4 \pm 0.8$ and $2.7 \pm 0.6$, respectively (Fig. 1). On the other hand, in HuCIII/ CETPTg, HuAI/CIIITg, and HuAI/CIII/CETPTg mice, the average number of aortic lesions per mouse was significantly lower than HuCIIITg and control mice: $0.9 \pm 0.4(P<0.01)$, $1.5 \pm 0.5(P<0.05)$ and $0.9 \pm 0.4(P<0.01)$, respectively (Fig. 1).

The mean lesion area per mouse in the different groups was 


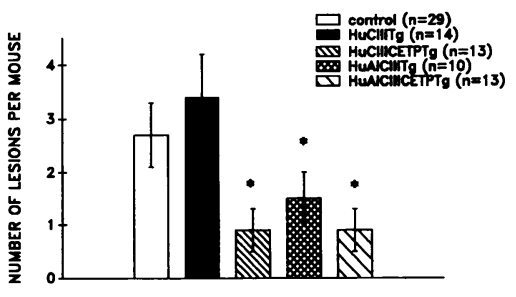

Figure 1. The average number of aortic lesions per mouse in controls, HuCIIITg, HuCIIICETPTg, HuAICIIITg, and HuAICIIICETPTg on high cholesterol diet for $16 \mathrm{wk}$. The average number of aortic lesions in HuCIIITg and control was not significantly different: $3.4 \pm 0.8$ and $2.7 \pm 0.6$, respectively. In the HuCIIICETPTg, HuAICIITT, and HuAICIIICETPTg, the average number of aortic lesions was significantly lower: $0.9 \pm 0.4(P<0.01), 1.5 \pm 0.5(P<0.05)$, and $0.9 \pm 0.4(P$ $<0.01$ ), respectively, as determined by ANOVA.

next analyzed. The mean lesion area per mouse (log transformed) is $48 \%$ higher in the hypertriglyceridemic HuCIIITg mice compared to controls $(P<0.05$, Fig. 2$)$. The introduction into the HuCIIITg mice of the human CETP transgene (HuCIII/ CETPTg mice), of the human apo A-I transgene (HuAI/CIIITg mice), or both transgenes (HuAI/CIII/CETPTg mice) resulted in reductions in the mean lesion area per mouse by $55 \%(P$ $<0.005), 50 \%(P<0.01)$, and $62 \%(P<0.005)$, respectively (Fig. 2). Thus, both human A-I and human CETP decrease the severity of atherosclerosis produced after $16 \mathrm{wk}$ of the atherogenic diet.

Animals appeared grossly normal after death; however, the prevalence of gallstones was higher in HuCIIITg mice (86\%), compared to control $(53 \%)(P<0.05)$. The introduction of human apo A-I or CETP to HuCIIITg mice also reduced the prevalence of gallstones to $50 \%$ in both HuCIII/CETPTg and HuAI/CIIITg mice $(P<0.05)$. The introduction of both genes to HuCIIITg mice caused even greater reductions in the prevalence of gallstones to $21 \%$ in $\mathrm{HuAI} / \mathrm{CIII} / \mathrm{CETPTg}$ mice ( $P$ $<0.005$ ).

Since the results of our study appeared to be in conflict with an earlier report showing an increase in atherosclerosis in simian CETP transgenic mouse (23), we carried out a separate study in which human CETP transgenic $(n=6)$ or control $(n=4)$ mice of similar mixed genetic background were fed the high cholesterol diet for $7 \mathrm{mo}$. Quantitation of atherosclerotic lesions in the proximal aorta showed a 2.2-fold increase in mean lesion area in human CETP trangenic mice compared to control mice $(P<0.04$ by ANOVA or $t$ test $)$.

\section{Discussion}

The primary objective of this study was to assess the effect of CETP expression on the development of atherosclerosis in the high triglyceride low HDL-C mouse model (15) which resembles a common human dyslipidemia. We found that CETP expression inhibited the development of early atherosclerotic lesions in the proximal aorta of hypertriglyceridemic mice. The CETP effect was consistently measured as fewer mice with lesions, a lower number of lesions per mouse, and a decreased mean lesion area. The antiatherogenic effect of CETP expression occurred despite lower HDL cholesterol levels, suggesting that CETP may enhance overall reverse cholesterol transport, even while lowering HDL levels. However, as in an earlier study (23), CETP expression in the absence of hypertriglyceridemia resulted in an increase in atherosclerosis, indicating that the results of CETP expression depend on the metabolic context.

We have also demonstrated that on a high cholesterol diet,

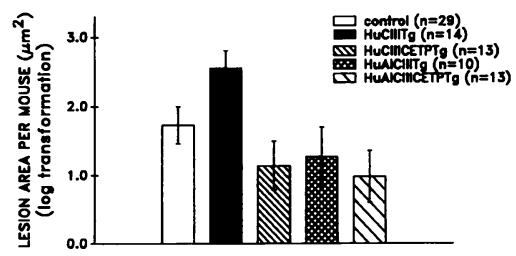

Figure 2. Quantitative analysis of atherosclerosis in controls, HuCIITg. HuCIIICETPTg, HuAICIIITg, and HuAICIIICETPTg on high cholesterol diet for $16 \mathrm{wk}$.

Mean lesion area was determined in the proximal aorta by quantitation of intimal lipid accumulation from Oil-red-O-stained sections according to the method of Rubin et al. Statistical analysis (one-way ANOVA, log transformation) indicates the mean lesion area per mouse is $48 \%$ higher in HuCIIITg mice, compared to controls $(P<0.05)$. The introduction in the HuCIITg mice, the human CETP transgene, of the human apo A-I transgene, or both, resulted in reduction in the mean lesion area by $55 \%(P<0.005)$, $50 \%(P<0.01)$, and $62 \%(P<0.005)$, respectively. Statistical significance was determined by ANOVA.

hypertriglyceridemic mice have a significantly larger mean lesion area compared to their control littermates, but the effect is small considering the high levels of triglycerides in these animals. Another line of HuCIIITg mice (2721 line) with even higher expression of human apo C-III and higher triglyceride levels (17) had a further increase in mean lesion area per mouse compared to controls (data not shown). The relation between hypertriglyceridemia and risk of atherosclerosis and coronary artery disease is controversial, and this study suggests a modest direct effect of hypertriglyceridemia on atherogenesis.

An incidental finding in our study was a higher prevalence of gallstones in the hypertriglyceridemic mice compared to controls, and a lower prevalence with apo A-I and CETP expression. The mechanism is unknown, but it is interesting to note that humans with familial hypertriglyceridemia have an increased risk of cholelithiasis $(24,25)$, associated with a smaller bile salt pool (26)

In contrast to the present findings, Marotti et al. (23) demonstrated that transgenic mice expressing cynomolgus monkey CETP had significantly more early atherosclerotic lestions in the proximal aorta, compared to controls when fed a high cholesterol diet. The reasons for the different findings appear to be related to the presence of hypertriglyceridemia in our model due to the presence of the apo C-III transgene. In our study, CETP levels were lower and comparable to human CETP levels $(2-4 \mu \mathrm{g} / \mathrm{ml})$ but the effects of CETP were amplified by expression in the context of hypertriglyceridemia. Both approaches achieved comparable reduction of $\operatorname{HDL}-\mathrm{C}(14,23)$. However, CETP expression in hypertriglyceridemic animals produces a much greater reduction in HDL size (14). These small HDL particles may be optimal mediators of cellular cholesterol efflux (27).

In the earlier study (20), an inbred strain of C57BL/6 was used compared to the mixed C57BL6/J $\times \mathrm{CBA} / \mathrm{J}$ background in our study. The contribution of this difference to the different results in both studies is doubtful, and in our experiments, possible uncontrolled genetic variation was compensated for by studying large number of animals. A shortcoming of both these studies is that only atherosclerotic lesions in the proximal aorta were assessed and these lesions were very small. In the future the effects of CETP expression in more robust gene knock-out models of murine atherosclerosis will be assessed such as apo E-deficient mice (22).

Human apo A-I expression has been shown to inhibit the development of early atherosclerotic lesions in C57BL/6 mice 
(20). Subsequently, it was shown that crossbreeding of HuAITg mice with the atherogenic apo E-deficient mice inhibited the development of more advanced forms of atherosclerosis (28, 29). In the present study, we also observed a protective effect of apo A-I against atherosclerosis in the hypertriglyceridemic HuAI/CIIITg mice. We found that CETP expression in the hypertriglyceridemic mice has an antiatherogenic effect comparable to that of human apo A-I, despite opposite effects on HDL-C levels (Table II, Figs. 1 and 2). These studies suggest that the dynamics of HDL cholesterol metabolism are equally as important as HDL levels in determining effects on atherosclerosis.

There are several possible mechanisms by which CETP may inhibit the development of atherosclerosis. One proposed mechanism is the enhanced catabolism of HDL-C induced by CETP, which may promote reverse cholesterol transport of cholesterol from the artery wall to the liver (14). CETP may promote a hetero exchange of HDL CE for VLDL triglyceride; subsequent lipolysis by hepatic lipase may produce smaller HDL particles (30). The formation of small HDL species may result in enhanced ability to promote cholesterol efflux from cells in arteries. Also, CETP induces depletion of free cholesterol (FC) and reduction of $\mathrm{FC} / \mathrm{CE}$ ratio in all lipoproteins perhaps due to stimulation of lecithin:cholesterol acyltransferase (LCAT) activity in vivo (13). The depletion of FC in lipoproteins may reduce net influx or enhance net efflux of cholesterol between plasma and arterial cells. Other less certain possibilities could be local synthesis of CETP in lesions which may increase cholesterol efflux from the artery to the liver.

Consistent with our findings in transgenic mice, recent findings in human genetic CETP deficiency indicate an increase in the susceptibility to coronary heart disease (31). Even though subjects with genetic CETP deficiency have increased HDL-C and apo A-I levels, they have an increased prevalence of coronary artery disease (31). Thus, the results of CETP expression in the hypertriglyceridemic model appear to be relevant to human pathophysiology.

\section{Acknowledgments}

This work was supported by National Institutes of Health grants HL22682, HL-33714, HL-45095, and HL-32435.

\section{References}

1. Morton, R. E., and D. B. Zilversmit. 1983. Inter-relationship of lipid transferred by the lipid-transfer protein isolated from human lipoprotein-deficient plasma. J. Biol. Chem. 258:11751-11757.

2. Albers, J. J., J. H. Tollefson, C. Chen, and A. Steinmetz. 1984. Isolation and characterization of human plasma lipid transfer proteins. Arteriosclerosis. 4:49-58.

3. Tall, A. R. 1986. Plasma lipid transfer proteins. J. Lipid Res. 27:361-367.

4. Inazu, A., M. L. Brown, C. B. Hesler, L. B. Agellon, J. Koizumi, K. Takata, Y. Maruham, H. Mabuchi, and A. R. Tall. 1990. Increased high density lipoprotein levels caused by common cholesteryl-ester transfer protein gene mutation. $N$. Engl. J. Med. 323:1234-1238.

5. Gordon, D. J., and B. M. Rifkind. 1989. High density lipoprotein: the clinical implications of recent studies. N. Engl. J. Med. 321:1311-1316.

6. Castelli, W. P., R. J. Garrison, P. W. F. Wilson, R. D. Abbott, S. Kulonsdiun, and W. B. Kannel. 1986. Incidence of coronary heart disease and lipoprotein cholesterol levels. J. Am. Med. Assoc. 256:2835-2838.

7. Miller, N. E. 1987. Association of high-density lipoprotein subclasses and apolipoproteins with ischemic heart disease and coronary atherosclerosis. Am. Heart J. 113:589-597.

8. Barter, P. J., G. J. Hopkins, and G. D. Calvert. 1982. Transfers and ex- changes of esterified cholesterol between plasma lipoproteins. Biochem. J. 208:17.

9. Fielding, P. E., C. J. Fielding, R. J. Havel, J. P. Kane, and P. Tun. 1983 Cholesterol net transport esterification and transfer in human hyperlipidemic plasma. J. Clin. Invest. 71:449-460.

10. Walsh, A., Y. Ito, and J. L. Breslow. 1988. High levels of human apolipoprotein A-I in transgenic mice result in increased plasma levels of small high density lipoprotein (HDL) particles comparable to human $\mathrm{HDL}^{3}$. J. Biol. Chem. 264:6488-6494.

11. Chajek-Shaul, T., T. Hayek, A. Walsh, and J. L. Breslow. 1991. Human apo A-I expression in transgenic mice alters HDL particle size distribution and diminishes selective uptake of HDL cholesteryl esters. Proc. Natl. Acad. Sci. USA. 88:6731-6735.

12. Rubin, E. M., B. Y. Ishida, S. M. Clift, and R. M. Kraus. 1991. Expression of human apolipoprotein A-I in transgenic mice results in reduced plasma levels of murine apolipoprotein A-I and the appearance of two new high density lipoprotein size subclasses. Proc. Natl. Acad. Sci. USA. 88:434-438.

13. Agellon, L. B., A. Walsh, T. Hayek, P. Moulin, X. L. Jiang, S. A. Shelanski, J. L. Breslow, and A. R. Tall. 1991. Reduced high density lipoprotein cholesterol in human cholesteryl ester transfer protein transgenic mice. J. Biol. Chem 266:10796-10801.

14. Hayek, T., T. Chajek-Shaul, A. Walsh, L. B. Agellon, P. Moulin, A. R. Tall, and J. L. Breslow. 1992. An interaction between the human cholesteryl ester transfer protein (CETP) and apolipoprotein A-I genes in transgenic mice results in a profound CETP-mediated depression of high density lipoprotein cholesterol levels. J. Clin. Invest. 90:505-510.

15. Hayek, T. N. Azrolan, R. B. Verdery, A. Walsh, T. Chajek-Shaul, L. B. Agellon, A. R. Tall, and J. L. Breslow. 1993. Hypertriglyceridemia and cholesteryl ester transfer interact to dramatically alter high density lipoprotein levels, particle sizes and metabolism. J. Clin. Invest. 92:1143-1152.

16. Aalto-Setala, K., E. A. Fisher, X. Chen, T. Chajek-Shaul, T. Hayek, R. Zechner, A. Walsh, R. Ramakrishnan, H. N. Ginsberg, and J. L. Breslow. 1992. Mechanism of hypertriglyceridemia in human apo CIII transgenic mice: diminished fractional catabolic rate associated with increased apo CIII and reduced apo $\mathrm{E}$ on the particles. J. Clin. Invest. 90:1889-1900.

17. Ito, Y., N. Azrolan, A. O'Connell, A. Walsh, and J. L. Breslow. 1990. Hypertriglyceridemia as a result of human apo CIII gene expression in transgenic mice. Science (Wash. DC). 249:790-793.

18. Walsh, A., N. Azrolan, K. Wang, A. Marcigliano, A. O'Connell, and J. L. Breslow. 1993. Intestinal expression of the human apo A-I gene in transgenic mice is controlled by a DNA region $3^{\prime}$ to the gene in the promoter of the adjacent convergently transcribed apo CIII gene. J. Lipid Res. 34:617-623.

19. Paigen, B., A. Morrow, P. A. Holmes, D. Mitchell, and R. A. Williams. 1987. Quantitative assessment of atherosclerotic lesions in mice. Atherosclerosis. 68:231-240.

20. Rubin, E. M., R. M. Krauss, E. A. Spangler, J. G. Verstuyft, and S. M. Clift. 1991. Inhibition of early atherogenesis in transgenic mice by human apolipoprotein A-I. Nature (Lond.). 353:265-267.

21. Marcel, Y., L. R. McPherson, M. Hogue, H. Czarnecka, Z. Zawudski, P. K. Weech, M. E. Whillock, A. R. Tall, and R. W. Milne. 1990. Distribution and concentration of cholesteryl ester transfer protein in plasma of normolipidemic subjects. J. Clin. Invest. 85:10-12.

22. Plump, A. S., J. D. Smith, T. Hayek, K. Aalto-Setala, A. Walsh, J. G. Verstuyft, E. M. Rubin, and J. L. Breslow. 1992. Severe hypercholesterolemia and atherosclerosis in apolipoprotein E-deficient mice created by homologous recombination in ES cells. Cell. 71:343-353.

23. Marotti, K. R., C. K. Castle, Y. P. Boyle, A. H. Lin, R. W. Murray, and G. W. Melchior. 1993. Severe atherosclerosis in transgenic mice expressing simian cholesteryl ester transfer protein. Nature (Lond.). 364:73-75.

24. Einarsson, K., K. Hellstrom, and M. K. Kallner. 1975. Gallbladder disease in hyperlipoproteinemia. Lancet. i:484-487.

25. Jergenson, T. 1989. Gallstones and plasma lipids in the Danish population. Scand. J. Gastroenterol. 24:916-922.

26. Duane, W. O. 1995. Abnormal bile and absorption in familial hypertriglyceridemia. J. Lipid Res. 36:96-107.

27. Fielding, C. J., and P. E. Fielding. 1995. Molecular physiology of reverse cholesterol transport. J. Lipid Res. 36:211-228.

28. Plump, A. S., C. Scott, and J. L. Breslow. 1995. Human apolipoprotein A-I gene expression raises HDL and suppresses atherosclerosis in apo E deficient mice. Proc. Natl. Acad. Sci. USA. 91:9607-9611.

29. Paszty, C., N. Maeda, J. Verstuft, and E. M. Rubin. 1994. Apolipoprotein AI transgene corrects apolipoprotein $\mathrm{E}$ deficiency-induced atherosclerosis in mice. J. Clin. Invest. 94:899-903.

30. Barter, P., and K.-A. Rye. 1994. Cholesteryl ester transfer protein: its role in plasma lipid transport. Clin. Exp. Pharmacol. Physiol. 21:663-672.

31. Yamashita, S., J. Hirano, M. Ishigami, T. Arai, S. Sakai, S. Nazaki, K Takemura, and Y. Matsuzawa. 1994. Marked hyperalphalipoproteinemia (HALP) due to a combined reduction in cholesteryl ester transfer protein (CETP) and hepatic triglyceride lipase (HTGL) is accompanied by atherosclerotic cardiovascular diseases (ACD). Circulation. 90:I-510. 